\title{
A STUDY OF PRIMARY ORBITAL IMPLANTS FOLLOWING EVISCERATION SURGERY
}

\author{
Gautam Paul' ${ }^{1}$ Zakir Hussain Laskar², Ankita Narula ${ }^{3}$
}

${ }_{1}^{1}$ Associate Professor, Department of Ophthalmology, Silchar Medical College, Silchar, Assam, India.

2Registrar, Silchar Medical College, Silchar, Assam, India.

3Postgraduate Student, Department of Ophthalmology, Silchar Medical College, Silchar, Assam, India.

ABSTRACT
BACKGROUND
Eye is known to be the most important sensory organ of communication and expression of our feelings. Loss of this organ may lead
to impairment of vision, disfigurement and psychological trauma. Evisceration is a destructive surgical procedure, in which
intraocular contents are removed along with inner two coats, retaining the sclera and optic nerve.
Aim- To study the surgical outcome among different types of primary orbital implants following evisceration surgery and find out
incidence of complications associated with them.

\section{MATERIALS AND METHODS}

20 cases were selected during 2 years period (May 2016 - April 2018) with various indications for evisceration. Patients' records were kept for demographics, surgical indications, implant types, follow-up and any reported complications after surgeries. Patients with a minimum of 6 months follow-up period were included in the study. Evaluation was done among various types of implants used, their associated complications and the patient's satisfaction following surgery.

Design- A prospective observational study.

\section{RESULTS}

A total of 20 patients (aged between 19- and 73-year-old) underwent evisceration with primary orbital implant during 2016- 2018. The most common indications for the surgical intervention were painful blind eye attributable to trauma (45\%) followed by infection and inflammation (40\%), primary glaucoma (5\%) and others (10\%). Out of 20 patients, PMMA implant was implanted in 10 patients $(50 \%)$, hydroxyapatite in 5 patients $(25 \%)$ and silicone implant in 5 patients (25\%). Implant motility was slightly better in patients with hydroxyapatite implants when compared to PMMA and silicone implants. No significant complications were noted except for one case of orbital implant exposure, who was given hydroxyapatite implant (18 mm). Most of the patients were satisfied and happy with the results.

\section{CONCLUSION}

Primary orbital implants provide an excellent way to replace the volume loss following evisceration surgery. Provided the proper technique is used for surgery, good motility and cosmesis can be achieved postoperatively without significant complications.

\section{KEY WORDS}

Evisceration Procedures, Orbital Implant, Implant Motility, Complications and Orbital Implant Exposure.

HOW TO CITE THIS ARTICLE: Paul G, Laskar ZH, Narula A. A study of primary orbital implants following evisceration surgery. J. Evolution Med. Dent. Sci. 2018;7(44):4749-4753, DOI: 10.14260/jemds/2018/1060

\section{BACKGROUND}

Eye is known to be the most important sensory organ of communication and expression of our feelings. Loss of this organ may lead to impairment of vision, disfigurement and psychological trauma. Evisceration is a destructive surgical procedure, in which intraocular contents are removed along with inner two coats, retaining the sclera and optic nerve. There are various indications of evisceration. The volume lost by the eviscerated eye can be replaced by orbital implants, which impart motility to the artificial eye or the prosthesis and maintain cosmetic symmetry with the fellow eye.

'Financial or Other Competing Interest': None.

Submission 20-08-2018, Peer Review 10-10-2018,

Acceptance 17-10-2018, Published 29-10-2018.

Corresponding Author:

Dr. Gautam Paul,

Flat No. $3 E$

Tista Apartment,

College Road, Silchar-788004,

Assam, India.

E-mail: gpophth4@gmail.com

DOI: $10.14260 /$ jemds $/ 2018 / 1060$
Various types of orbital implants are available, such as porous and non-porous. The artificial eye is typically fit 5 to 6 weeks following surgeries or when the eye socket swelling has subsided. The artificial eye covers the eye socket and underlying orbital implant. Ocularists, the artificial eye makers make a custom impression of patient's eye socket in order to obtain an ideal fit. The ocularist hand paints the iris colour to correspond to the patient's normal eye. Fine red threads and other specialised techniques are utilised to stimulate naturally appearing veins and arteries.

\section{Aim of the Study}

To study the surgical outcome among different types of primary orbital implants following evisceration and find out incidence of complications associated with them.

\section{Review of Literature}

Orbital implants replace the volume lost by the eviscerated eye, provide motility to the prosthesis and maintain cosmetic symmetry with the fellow eye.

Various types of orbital implants are available. Nonporous implants such as PMMA and silicone do not allow direct and indirect integration with the orbital structures or 
with the prosthesis. Such implants have no direct attachment to the prosthesis and are the commonest implants used today.(1) They have the advantage of being inexpensive, welltolerated and have very few complications. The recent trend of wrapping such implants in sclera and attaching the extraocular muscles to the sclera give them a better centering and a better prosthesis motility.(2)

Porous (Synthetic semi-integrated) implants are integrated mechanically with the orbital structure, but not with the prosthesis and are associated with a higher rate of implant exposure.

A new era in orbital implants begun when the coralline hydroxyapatite received FDA approval in 1989 after the clinical work on integrated orbital implants by Penry. Hydroxyapatite, a complex calcium-phosphate salt Ca10 (PO4) $6(\mathrm{OH}) 2$, is a component of human bone. This porous implant is obtained from reef building coral. It gets incorporated in the orbital tissue forming fibrous growth and thus provides better motility and reduces the chances of displacement and extrusion. The use of hydroxyapatite significantly raises the cost of surgery.

Implant exposure (1\% to $15 \%)$ seems to be a major complication with hydroxyapatite implant, because of its rough surface.(3) Variation in surgical procedures is the reason for vastly different results. Proper sizing of the implant and meticulous wound closure helps to minimise the risk of implant exposure.

Porous polyethylene is another biointegrated implant material with a pore size of 400 microns, which allows a fibrovascular ingrowth.(4) The risk of implant exposure can be minimised without interfering with fibrovascular ingrowth using the recent scleral cap technique, in which the implant surface is covered anteriorly with donor or autologous sclera of $10-12 \mathrm{~mm}$ diameter.(5)

\section{Size of the Implant}

Implant sizing should be proper. Size that provides around $65 \%-70 \%$ of volume replacement is ideal, so that the remaining $30 \%-35 \%$ can be contributed by the prosthesis.

A smaller implant has a higher chance of displacement or migration and developing superior sulcus deformity. A larger implant is known to improve the cosmesis and motility. However, an inappropriately large implant may produce tension on the conjunctival wound and result in wound gape and implant exposure. Generally, a $16-18 \mathrm{~mm}$ size is chosen by most of the surgeons. A recent trend is to use the axial length in fellow eye (Axial length in $\mathrm{mm}-2=$ implant diameter in $\mathrm{mm}$ ) to choose the implant size.(6) One should remember to deduct an additional $2 \mathrm{~mm}$ from the axial length if the implant is traditionally wrapped, but not when the scleral cap technique is used.

\section{MATERIALS AND METHODS}

A prospective observational study was carried out in the Department of Ophthalmology, Silchar Medical College for a period of two years from May 2016 to April 2018. 20 patients were included in the study who had evisceration surgery with primary orbital implant with a minimum follow-up period of 6 months. Patients with bleeding disorders, dacryocystitis, other septic foci and compromised conjunctiva were excluded from the study. Collected data included patient demographics, diagnosis necessitating evisceration, procedure undertaken, axial lengths of both eyes, size of implant, follow-up duration and any complications encountered and their treatment. The same surgical technique was used in all the patients. Written and informed consent for the surgery was taken from all the patients. A preoperative evaluation with regards to detailed history and examination including visual acuity, slit lamp examination, ocular motility and lab investigation.

\section{Surgical Technique}

Under local anaesthesia, a universal eye speculum was placed between the eyelids. A 360-degree conjunctival peritomy was done just posterior to the corneal limbus, the sclera was incised circumferentially $1-2 \mathrm{~mm}$ from the limbus with No. 11 scalpel blade and a corneal button was removed. An evisceration spoon was used to separate the uveal tissue from the sclera and the intraocular contents were removed. The interior of the scleral shell was scraped with a blade and scrubbed with alcohol to remove all uveal tissue remnants.

Four full-thickness relaxing incisions were made in the sclera, between the rectus muscle insertions, to the equator. An implant size was chosen that would allow tension-free closure of the anterior ocular tissue, 4-6 mm less than the axial length of the contralateral eye. In most cases, either 16 or $18 \mathrm{~mm}$ implant was placed.



Figure 1. An Eviscerated Globe with Full Thickness Relaxing Incisions

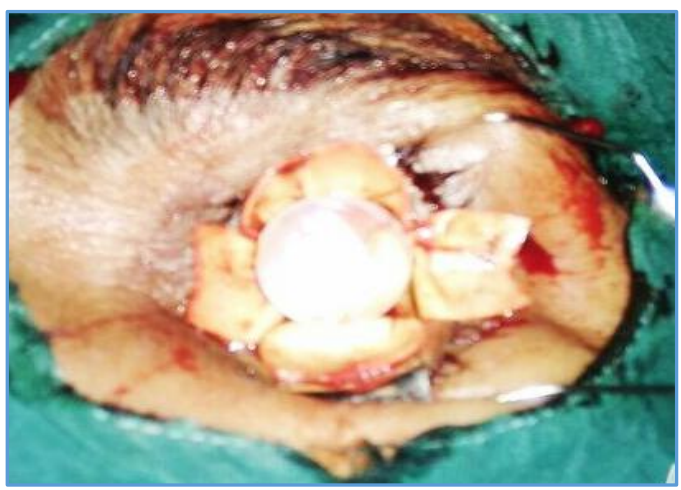

Figure 2. Placement of Implant in Scleral Cavity

The implant was placed in the scleral cavity followed by suturing of the edges of the superior and inferior scleral flaps together horizontally in front of the implant with 5-0 Vicryl. Then, vertical suturing of the edges of medial and the lateral scleral flaps was done. The Tenon capsule was closed with interrupted 5-0 Vicryl suture, and the conjunctiva was closed with a running 6-0 Vicryl suture without producing any tension. Antibiotics were injected into the inferior 
subconjunctival space and antibiotic ointment was placed on the ocular surface. Topical antibiotics were used for the next 3 - 4 weeks and oral antibiotics were prescribed for 1 week. A prosthesis made of plastic was fabricated 6 weeks after surgery.

\section{Follow-Up}

Regular follow-up of the patients after the operation were done on day 1, day 3, 1 week, 2 weeks, 1, 3 and 6 months. During follow-up periods, patients were examined for any inflammation, infection, presence of migration or exposure of the implant or any deep superior sulcus deformity. At $3^{\text {rd }}$ postoperative month, conjunctival excursion was measured to evaluate the implant motility. After removing prosthesis, the patient was asked to look in all the extreme gazes after center of the conjunctiva was marked. The amount of vertical and horizontal movement of conjunctiva was measured with a ruler. To properly evaluate the cosmetic results, we asked each patient to rate their result at last follow-up, based on criteria as excellent (Satisfied with the results), good (Better than preoperative state) or poor (Dissatisfied with the results).

\section{RESULTS}

A total of 20 patients (16 men and 4 women) were included in the study. The age at presentation ranged between $19-72$ years.

\begin{tabular}{|c|c|c|}
\hline Indication for Evisceration & No. of Cases & \% Age \\
\hline $\begin{array}{c}\text { Painful blind eye, attributable to } \\
\text { trauma }\end{array}$ & 9 & 45 \\
\hline Infection and inflammation & 8 & 40 \\
\hline Primary glaucoma & 1 & 5 \\
\hline Other causes & 2 & 10 \\
\hline Total & 20 & 100 \\
\hline \multicolumn{3}{|c|}{$\begin{array}{l}\text { Table 1. Indications for Evisceration in Various Patients } \\
\text { were As Per Follows }\end{array}$} \\
\hline
\end{tabular}

\begin{tabular}{|c|c|c|c|c|c|}
\hline $\begin{array}{c}\text { Implant } \\
\text { Size } \\
(\mathbf{m m})\end{array}$ & $\begin{array}{c}\text { Mean AL } \\
(\mathbf{m m}) \\
\text { C/L Eye }\end{array}$ & Hydroxyapatite & Silicone & PMMA & Total \\
\hline 16 & 22.8 & 4 & 5 & 10 & 19 \\
\hline 18 & 24.4 & 1 & 0 & 0 & 1 \\
\hline Total & $\mathbf{5}$ & $\mathbf{5}$ & $\mathbf{1 0}$ & $\mathbf{2 0}$ \\
\hline Table 2. Various Implants used and the Axial Lengths of \\
the Contralateral Eyes \\
\hline
\end{tabular}

None of the implants was wrapped or pegged. End point of the follow-up was determined as the date of the last visit. The mean follow-up period was 6 months. Mean vertical and horizontal implant motility with various implants were noted (Table 3) and it was observed that the implant motility was better with hydroxyapatite implant when compared to PMMA and silicone implants and the latter two almost had similar motility.

\begin{tabular}{|c|c|c|}
\hline Type of Implant & $\begin{array}{c}\text { Mean Vertical } \\
\text { Motility (mm) }\end{array}$ & $\begin{array}{c}\text { Mean Horizontal } \\
\text { Motility (mm) }\end{array}$ \\
\hline Hydroxyapatite & $6.1 \pm 0.26$ & $8.5 \pm 0.15$ \\
\hline PMMA & $5.9 \pm 0.17$ & $8.2 \pm 0.22$ \\
\hline Silicone & $6.0 \pm 0.14$ & $8.0 \pm 0.16$ \\
\hline Table 3. Mean Implant Motility with Various Implants \\
\hline
\end{tabular}

During the postoperative follow-up period, various complications were looked for and the observations were as follows:

\begin{tabular}{|c|c|c|c|}
\hline Complications & $\begin{array}{c}\text { No. of } \\
\text { Patients }\end{array}$ & $\begin{array}{l}\text { Type and Size of } \\
\text { Implant (mm) }\end{array}$ & $\%$ Age \\
\hline Implant exposure & 1 & Hydroxyapatite(18) & 5 \\
\hline Implant & 0 & & \\
\hline Deep superior sulcus & 0 & & \\
\hline Mild discharge & 2 & PMMA(16) & 10 \\
\hline Ptosis & 0 & & \\
\hline \multicolumn{4}{|c|}{$\begin{array}{l}\text { Table 4. Various Complications with different Types of } \\
\text { Implants }\end{array}$} \\
\hline
\end{tabular}

One of the patients revealed wound gaping and implant exposure. None of the cases had implant migration or sympathetic ophthalmia or deep superior sulcus deformity or ptosis (defined as difference of the marginal reflex distance in both eyes of more than $1 \mathrm{~mm}$ ). Other complications noted were mild discharge $(n=2 ; 10 \%)$.

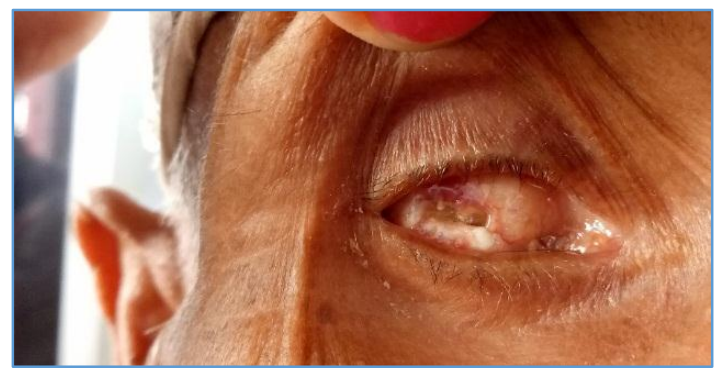

Figure 3. Patient with Implant Exposure

The greatest number of the patients evaluated their result as-

\begin{tabular}{|c|c|c|c|c|}
\hline $\begin{array}{c}\text { Patients } \\
\text { Response }\end{array}$ & \multicolumn{3}{|c|}{$\begin{array}{c}\text { No. of Patients with Implants } \\
\text { HP PMMA Silicone }\end{array}$} & \% Age \\
\hline Excellent & 4 & 5 & 2 & 55 \\
\hline Good & 1 & 5 & 3 & 45 \\
\hline Poor & 0 & & & 0 \\
\hline Total & \multicolumn{5}{|c|}{$\mathbf{2 0}$} & $\mathbf{1 0 0}$ \\
\hline Table 5. Patient's Response After Surgery \\
\hline
\end{tabular}

The implant mobility and cosmetic appearance and of ocular prostheses were satisfactory (Fig. 4 (A-D)).

\section{Figure 4. Happy Patient after Surgery}

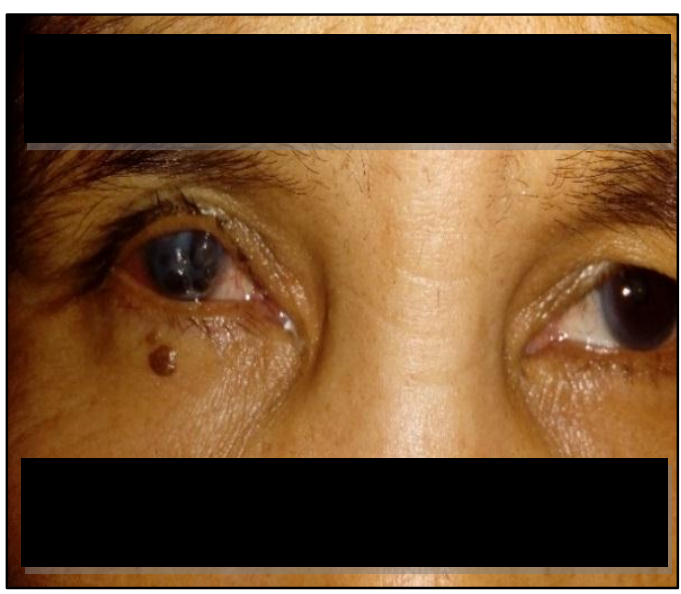

Figure 4A. Preoperative Photograph 




Figure 4B. Postoperative Day 1

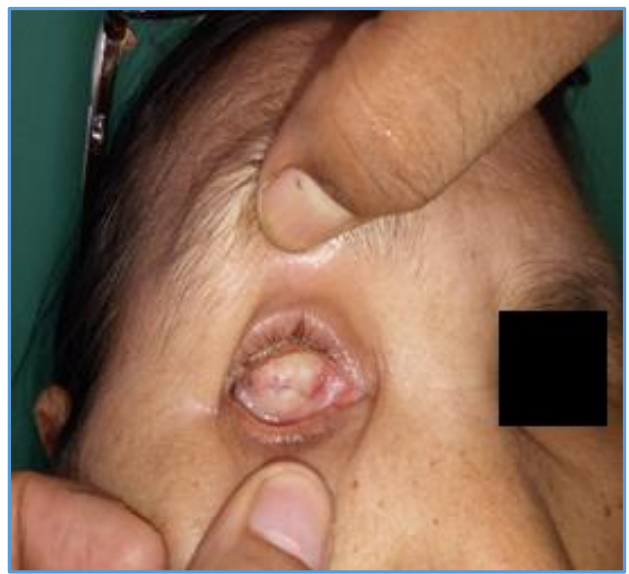

Figure 4C. Postoperative 6th Week

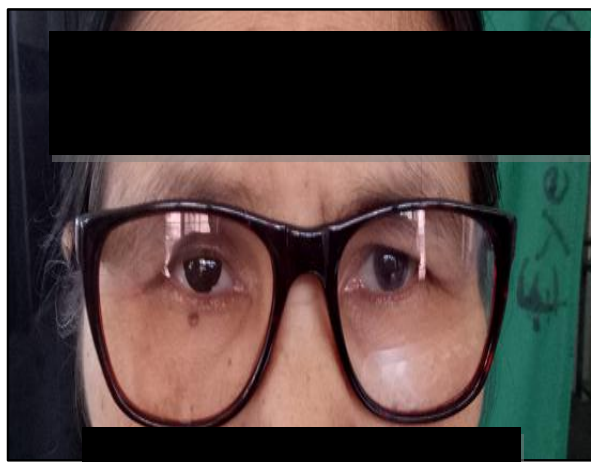

Figure 4D. Postoperative with Prosthesis

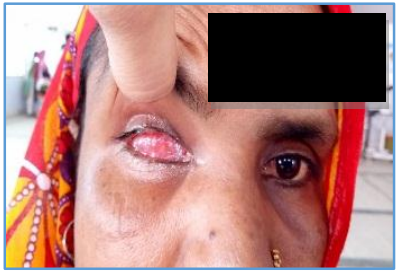

Fig. $5 a$

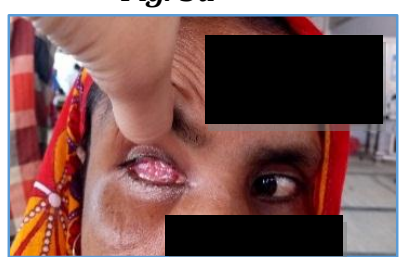

Fig. $5 c$

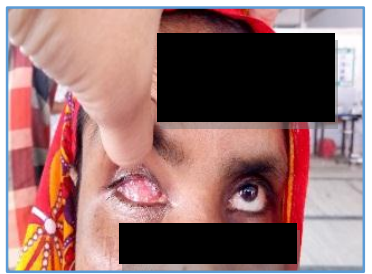

Fig. $5 b$



Fig. $5 d$
Figure 5. Photograph of the Right Eye with Good Results after Evisceration with Acrylic Implant. (A) Primary gaze, (B) Upward gaze, (C) Right gaze, (D) Left gaze

\section{DISCUSSION}

The benefits of evisceration surgery are less disruption of orbital anatomy, relative preservation of the scleral tissue, reduced bleeding, better cosmesis and superior motility in patients with a similar implant undergoing enucleation surgery; (Dortzbach and Woog 1985). Moreover, in cases of endophthalmitis, it may prevent the spread of infection to orbit and central nervous system (Jordan and Parisi 1996; Tari et al 2009).

However, two major risks of evisceration surgery are anophthalmic socket syndrome and implant exposure (Moshfeghi etal, 2000). Loss of orbital volume primarily results in Anophthalmic socket syndrome. To prevent this, it is necessary to place an implant of proper size within the sclera. However, standard evisceration procedures allow placement of a smaller implant (Soll 1982; Zolli 1988). Without modifying the procedure, placing a larger implant will increase the risk of its exposure. The main risk factors for exposure are inadequate surgical technique, high tension in the wound, larger implant and persistent conjunctival inflammation. Duong et al (2001) reported that an inappropriately large implant predisposes it to exposure. Several modifications have been tried in the evisceration technique with the aim of minimizing exposure rate and better fibrovascular growth. In this surgery, it is important to decrease tension on the surgical wound and at the same time reduce the volume loss. Various techniques have been recommended to achieve these goals: scleral flaps, relaxing scleral incisions, posterior sclerotomies, wrapping and others. ${ }^{(7,8,9)}$ Fibrovascular ingrowth in the implant begins at the sclerotomy sites.(10) Jordan and Yang et al(7) described a 'scleral quadrisection' procedure as a modification of standard evisceration. In this technique, the native sclera is quadrisected from the limbus to the optic nerve between the rectus muscle insertions. Massary and Holds performed two full-thickness sclerotomies from the anterior limbus incision to the optic nerve in the inferonasal and superotemporal quadrants to create two scleral flaps with release of the sclera from them.(9) They argued that it is important to close the sclera at the equator to avoid posterior migration of the nonbiointegratable implants. Similarly, Sales-Sanz and Sanz-Lopez performed four sclerotomies from the limbus to the optic nerve to form four separate scleral petals.

In our study one case of exposure was present, which could have resulted due to implant size itself. The tension present in the wound or improper surgical technique.

Estimated implant extrusion rates vary widely from zero to more than $20 \%$ according to different studies. Recent studies using scleral quadrisection or posterior sclerotomy showed lower implant extrusion rates (Table 2). Other factors in addition to the surgical technique such as implant size, post-operative wound care and duration of antibiotic therapy may result in implant extrusion.(11) 


\begin{tabular}{|c|c|c|c|c|}
\hline $\begin{array}{c}\text { Authors } \\
\text { (Year) }\end{array}$ & $\begin{array}{c}\text { No. of } \\
\text { Eyes }\end{array}$ & $\begin{array}{c}\text { Surgical } \\
\text { Technique }\end{array}$ & $\begin{array}{c}\text { Extrusion } \\
\text { Rate (\%) }\end{array}$ & Implant \\
\hline $\begin{array}{c}\text { Yang et al } \\
\text { (1997) }\end{array}$ & 0 of 17 & $\begin{array}{c}\text { Evisceration with } \\
\text { scleral } \\
\text { quadrisection }\end{array}$ & 0 & Hydroxyapatite \\
\hline $\begin{array}{c}\text { Sales-Sanz } \\
\text { and } \\
\text { Sanz-Lopez } \\
(2007)\end{array}$ & 0 of 65 & $\begin{array}{c}\text { Evisceration with } \\
\text { scleral } \\
\text { quadrisection }\end{array}$ & 0 & polyethylene \\
\hline Liu (2007) & 0 of 53 & $\begin{array}{c}\text { Evisceration with } \\
\text { posterior } \\
\text { sclerotomy }\end{array}$ & 0 & $\begin{array}{c}\text { Alloplastic } \\
\text { implant }\end{array}$ \\
\hline $\begin{array}{c}\text { Tari et al al } \\
\text { (2009) }\end{array}$ & 2 of 50 & $\begin{array}{c}\text { Evisceration with } \\
\text { scleral } \\
\text { quadrisection }\end{array}$ & 4 & $\begin{array}{c}\text { Acrylic } \\
\text { alloplastic } \\
\text { sphere }\end{array}$ \\
\hline Table 2. Comparison of Extrusion Rate after Evisceration \\
\hline
\end{tabular}

Ocular discharge was another complication occurring in 2 patients $(10 \%)$ and was probably the result of wearing an artificial eye with its surface rubbing frequently the conjunctival surface of the lids, resulting in production of mucus.

The evisceration followed by placement of various primary orbital implants is technically easy, quick and provides excellent and reproducible results and prevent volume loss and provide better cosmesis. Hydroxyapatite implants impart better implant motility, but increase the cost of the surgery. On the other hand acrylic and silicone implants provide good motility and cosmesis at a lower cost, which maximum people can afford.

\section{CONCLUSION}

Porous implants carry the theoretical benefit of promoting fibrous ingrowth to facilitate implant stability and also for allowing for placement of a peg system to couple the prosthesis directly to the orbital implant if desired. Most of the studies in past used porous implants and there are only a few studies which directly compared porous and non-porous implants. The reason may be based on the belief that fibrous ingrowth affords protection against migration. Both porous and non-porous implants were well tolerated. Complications were carefully examined in both implant groups and only one case with porous implant had implant exposure. The reported incidence of implant extrusion of non-porous implants in two studies ranging from $0 \%$ and $7.1 \%$. For porous implants, exposure rates were very low, ranging from $0 \%$ to $5.6 \%$. However, the rate of complications generally was comparable, suggesting that the choice of implant may not result in a major difference in complication rates.

\section{REFERENCES}

[1] Van Acker E, De Potter P. Porous polyethylene (Medpor) orbital implant. Prospective study of 75 primary implantations. J Fr D'ophthalmol 2001;24(10):1067-73.

[2] Trichopoulos N, Augsburger JJ. Enucleation with unwrapped porous and nonporous orbital implants: a 15 year experience. Ophthalmic Plastic Reconstructive Surgery 2005;21(5):331-6.

[3] Lin CJ, Liao SL, Jou JR, et al. Complications of motility peg placement for porous hydroxyapatite orbital implants. British J Ophthalmol 2002;86(4):394-6.

[4] Jordan DR, Bawazeer A. Experience with 120 synthetic hydroxyapatite implants (FC13). Ophthal Plast Reconstructive Surg 2001;17(3):184-90.

[5] Klett A, Gulthoff R. Muscle pedunculated scleral flaps. A microsurgical modification to improve prosthesis motility. Ophthalmologe 2003;100(6):449-52.

[6] Kaltrieder SA. The ideal ocular prosthesis: analysis of prosthetic volume. Ophthal Plast Reconstructive Surg 2000;16(5):388-92.

[7] Madill SA, Maclean H. Enucleation with Reverse replacement of sclera as an alternative to conventional evisceration. Orbit 2005;24(1):23-8.

[8] Sales-Sanz M, Sanz-Lopez A. Four-petal evisceration: a new technique. Ophthalmic Plastic \& Reconstructive Surgery 2007;23(5):389-92.

[9] Massry GG, Holds JB. Evisceration with scleral modification. Ophthalmic Plastic and Reconstructive Surgery 2001;17(1):42-7.

[10] Sarvananthan N, Liddicoat AJ, Fahy GT. Synthetic hydroxyapatite orbital implants: a clinical and MRI evaluation. Eye (Lond) 1999;13(Pt 2):205-8.

[11] Liu D. Evisceration techniques and implant extrusion rates: a retrospective review of two series and a survey of ASOPRS surgeons. Ophthalmic Plastic \& Reconstructive Surgery 2007;23(1):16-21. 